\title{
LA INFLUENCIA DEL GÉNERO SOBRE LA RESPONSABILIDAD SOCIAL EMPRESARIAL EN LAS ENTIDADES DE ECONOMÍA SOCIAL
}

\author{
POR \\ Inocencia María MARTÍNEZ LEÓN ${ }^{1}$ \\ Narciso ARCAS LARIO ${ }^{2}$ \\ Margarita GARCÍA HERNÁNDEZ ${ }^{3}$
}

\section{RESUMEN $^{4}$}

Puesto que las Entidades de la Economía Social (EES) basan su funcionamiento en valores como la democracia, la igualdad, la equidad, la solidaridad y, por tanto, contrarios a toda clase de discriminación, cabria esperar que prevaleciera en todos sus ámbitos la igualdad de género y, en especial, en lo relativo a la toma de decisiones. Sin embargo, al igual que sucede en el conjunto de las empresas, los escasos estudios que existen ponen de manifiesto que en las EES la participación de hombres y mujeres en la toma de decisiones no es igualitaria. Parece que estas organizaciones no son ajenas a los efectos de la segregación vertical, fundamentados en diversas teorías explicativas. No obstante, el estilo directivo femenino es bien diferente al desarrollado por sus colegas masculinos, aunque la cultura empresarial y los estereotipos de género impiden su diferenciación efectiva.

\footnotetext{
${ }^{1}$ Universidad Politécnica de Cartagena. Dirección de correo electrónico: ino.martinez@upct.es

${ }^{2}$ Universidad Politécnica de Cartagena. Dirección de correo electrónico: arcas.lario@upct.es

${ }^{3}$ Universidad Politécnica de Cartagena. Dirección de correo electrónico: margaghdez@yahoo.es

4 Este trabajo es resultado del proyecto de investigación con número de expediente F09174, financiado por el Ministerio de Trabajo e Inmigración conforme a la Orden TIN/970/2009, de 6 de abril.
}

REVESCO Nº 105 - MONOGRÁFICO: La economía social y la igualdad de género -

ISSN: 1885-8031 - www.ucm.es/info/revesco

DOI: 10.5209/rev_REVE.2011.v105.6

Fecha de recepción: 03/12/2010

Fecha de aceptación: 01/03/2011 
Por otra parte, la sociedad exige cada vez más a las empresas compromisos sociales y medioambientales que superan el ámbito estrictamente económico. Por ello, a las empresas en general, y a las de la Economía Social en particular, se les pide que adopten prácticas de Responsabilidad Social Empresarial (RSE). En este contexto, y ante el paralelismo que existe entre los valores y principios de la Economía Social y de la Responsabilidad Social Empresarial (RSE), este trabajo tiene como objetivo analizar la incidencia del género en la RSE de las EES. Para ello, se cuenta con la información proporcionada de una muestra formada por 134 cooperativas y sociedades laborales. Los resultados obtenidos muestran que la mayor participación de las mujeres en la toma de decisiones de las empresas de Economía Social no afecta ni a la RSE, medida en su conjunto, ni a cada una de sus dimensiones (económica, social y medioambiental).

Palabras Clave: Igualdad de Género, Responsabilidad Social Empresarial, economía social, cooperativas, sociedades laborales.

Claves Econlit: M140, M190, P130, J700.

\title{
THE INFLUENCE OF GENDER ON CORPORATE SOCIAL RESPONSIBILITY IN SOCIAL ECONOMY ENTERPRISES
}

\begin{abstract}
The Social Economy Enterprises (SEE) operation, based on values such as democracy, equality, equity, solidarity and, consequently, opposed to all forms of discrimination, might be expected to guarantee the gender equality in all their areas, especially on the decisionmaking position. However, as it is frequently happening in the most of the business, the participation of men and women in decision-making is not equal in the SEE. These organizations are sensible to the effects of vertical segregation, according to several explanatory theories. Nonetheless, the female management style is quite different to their male colleagues, although the corporate culture and gender stereotypes difficult their effective differentiation.
\end{abstract}

REVESCO No 105 - MONOGRÁFICO: La economía social y la igualdad de género -

ISSN: 1885-8031 - www.ucm.es/info/revesco 
On the other hand, society demands more and more social and environmental commitments to the companies going beyond the economic sphere. Consequently, companies in general, and the SEE in particular, are required to adopt practices of Corporate Social Responsibility (CSR). In this context, given the parallelism between the values and principles of the Social Economy and Social Responsibility (CSR), this paper analyzes the gender impact on the CSR in the SEE. A sample of 134 cooperatives and worker-owned companies has been used. The findings show that increased participation of women in decision-making of Social Economy enterprises does not affect CSR as a whole or each of its dimensions (economic, social and environmental).

Keywords: Gender Equality, Job Segregation, Corporate Social Responsibility, social economy, cooperatives, worker-owned companies.

\section{INTRODUCCIÓN}

La progresiva incorporación de la mujer al mundo laboral no ha conseguido su presencia paritaria en las empresas, tanto públicas como privadas. La participación de las mujeres en los órganos de decisión es mucho más reducida que la de los hombres en cualquier empresa en general, y en las EES en particular. Este fenómeno, conocido como segregación vertical, supone la desigualdad entre hombres y mujeres en el acceso a puestos de responsabilidad y poder. Además, está provocando el desaprovechamiento del particular estilo directivo femenino, fundamental para la buena gestión de cualquier organización, entre ellas las de Economía Social.

Las EES basan su funcionamiento en valores como la democracia, la igualdad, la equidad y la solidaridad, lo que favorece que tengan una sensibilidad especial hacia los problemas, necesidades y demandas de las personas. Además, anteponen el ser humano y su desarrollo a otro tipo de cuestiones de carácter económico, ideológico, político o social. En consecuencia, se observa una relación clara y directa entre sus fundamentos y lo relacionado

REVESCO No 105 - MONOGRÁFICO: La economía social y la igualdad de género -

ISSN: 1885-8031 - www.ucm.es/info/revesco 
con la igualdad de género, dado que dichas entidades se configuran precisamente en base a principios contrarios a toda clase de discriminación.

Por otra parte, la sociedad exige cada vez más a las empresas compromisos sociales y medioambientales que superan el ámbito estrictamente económico. Por ello, a las empresas, y en particular las de la Economía Social, se les pide que adopten prácticas de Responsabilidad Social Empresarial (RSE) dirigidas a satisfacer las expectativas de sus diferentes grupos de interés, máxime cuando las mismas pueden explicar, en buena medida, el logro de ventajas competitivas (Arcas y Briones, 2009).

$\mathrm{Si}$, como se acaba de indicar, los valores de las EES hacen a estas organizaciones especialmente sensibles a las cuestiones relacionadas con la igualdad de género, no es menos cierto que el paralelismo existente entre estos mismos valores y los que sustentan la RSE justifican que las EES sean especialmente proclives a adoptar comportamientos socialmente responsables (Arcas y Briones, 2009). Sin embargo, la evidencia de estas conexiones entre los conceptos de Igualdad de Genero, Economía Social, y RSE contrasta con los escasos trabajos, sobre todo empíricos, que han centrado su interés en estudiar la relación que existe entre la presencia de mujeres en los órganos de decisión de las EES y los comportamientos socialmente responsables de estas organizaciones.

En este contexto, el objetivo de este trabajo es analizar de forma exploratoria, a partir de la información obtenida de una muestra formada por 134 cooperativas y sociedades laborales, en qué medida la Igualdad de Género influye en la gestión de la RSE de este tipo de organizaciones de la economía social (Figura 1).

Figura 1. Igualdad de Género y RSE

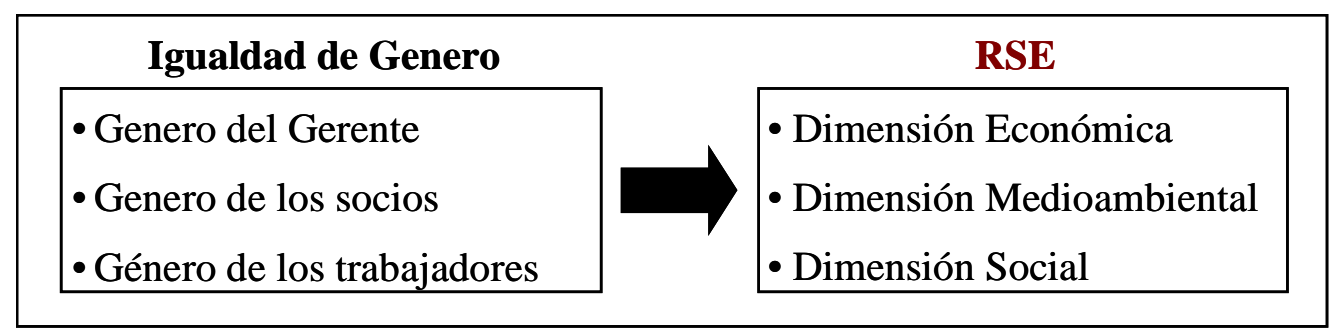

Fuente: Elaboración propia.

REVESCO No 105 - MONOGRÁFICO: La economía social y la igualdad de género -

ISSN: 1885-8031 - www.ucm.es/info/revesco 
Para conseguir este objetivo, el trabajo se estructura en siete apartados. En primer lugar se analiza el papel de la mujer en las entidades de economía social. A continuación se exponen las características del estilo directivo femenino, y de la responsabilidad social empresarial, respectivamente. Posteriormente se aborda la metodología para la realización del estudio empírico y los resultados del mismo, para finalizar con las principales conclusiones y la bibliografía utilizada.

\section{EL PAPEL DE LA MUJER EN LAS ENTIDADES DE ECONOMÍA SOCIAL: PARTICIPACIÓN EN LA TOMA DE DECISIONES}

\subsection{Participación de la mujer en las entidades de economía social}

La situación laboral de las mujeres en el ámbito de la Economía Social es, en su conjunto, manifiestamente mejor que en el resto de la economía, siendo la representación prácticamente paritaria (Tabla 1). Si nos fijamos en los datos sobre la evolución de la tasa de empleo en las organizaciones con mayor importancia dentro de la Economía Social, Cooperativas y Sociedades Laborales, ambas tienen entre sus trabajadores un porcentaje de mujeres superior al $40 \%$, estando más presentes en las sociedades laborales $(53,2 \%)$ que en las cooperativas $(46,8 \%)$.

Tabla 1. Tasa de empleo por sexo en las Entidades de Economía Social en España

\begin{tabular}{|l|c|c|c|c|c|c|c|c|c|c|}
\hline \multirow{2}{*}{$\begin{array}{c}\text { Forma } \\
\text { Jurídica }\end{array}$} & \multicolumn{2}{|c|}{$\mathbf{2 0 0 5}$} & \multicolumn{2}{c|}{$\mathbf{2 0 0 6}$} & \multicolumn{2}{c|}{$\mathbf{2 0 0 7}$} & \multicolumn{2}{c|}{$\mathbf{2 0 0 8}$} & \multicolumn{2}{c|}{$\mathbf{2 0 0 9}$} \\
\cline { 2 - 11 } & $\mathbf{\% H}$ & $\mathbf{\%} \mathbf{M}$ & $\mathbf{\% H}$ & $\mathbf{\%} \mathbf{M}$ & $\mathbf{\% H}$ & $\mathbf{\% M}$ & $\mathbf{\% H}$ & $\mathbf{\%} \mathbf{M}$ & $\mathbf{\% H}$ & $\mathbf{\%}$ \\
\hline Sociedad Laboral & 42,9 & 57,1 & 43,9 & 56,1 & 45,0 & 55,0 & 45,9 & 54,1 & 46,8 & 53,2 \\
\hline Cooperativa & 57,1 & 42,9 & 56,1 & 43,9 & 55,0 & 45,0 & 54,1 & 45,9 & 53,2 & 46,8 \\
\hline
\end{tabular}

Similares resultados obtiene la Confederación Española de Cooperativas de Trabajo Asociado (COCETA, 2004) en un estudio sobre la realidad social y laboral de las mujeres en el cooperativismo de trabajo asociado en España. Dicha publicación refleja que, en estas entidades, la proporción de mujeres sobre el total de la plantilla es inferior al de los hombres, representando el $48 \%$ de sus miembros.

REVESCO No 105 - MONOGRÁFICO: La economía social y la igualdad de género -

ISSN: 1885-8031 - www.ucm.es/info/revesco 
En términos globales, la participación de las mujeres en las EES es inferior a los hombres por las diferencias de orden sexual existentes en el ámbito laboral de los países desarrollados (Sajardo, Ribas, Benavent, Saz, Serra y Vilar, 2009). Esta realidad evidencia la existencia de dos fenómenos claramente definidos. De un lado, la segregación ocupacional horizontal, que supone la concentración de la actividad profesional en determinados oficios y profesiones, como manifestación de los estereotipos asociados a cada uno de los géneros en el mercado de trabajo (Ibáñez, 2008; 2010). Se explica así la desigual participación de hombres y mujeres según el sector, rama de actividad o tipo de trabajo (Sajardo et al., 2009). Por otro lado, la segregación vertical entendida como el desigual acceso a las diferentes categorías profesionales por parte de mujeres y hombres (Sajardo et al., 2009). Se manifiesta cuando las mujeres ocupan niveles organizativos más bajos que sus homólogos varones, y tienen menor presencia en los puestos de poder y de toma de decisiones en las organizaciones, pese a tener las mismas competencias y capacidades que ellos.

Tanto la segregación vertical como la horizontal tienen diferentes efectos sobre las distintas tipologías de empresa, ya que presentan desiguales estructuras laborales por sexo. En este sentido, la evidencia empírica disponible para el sector de la Economía Social muestra importantes desigualdades entre la participación laboral de hombres y mujeres en función del tipo de entidad (cooperativa, sociedad laboral, entidad no lucrativa de acción social, etc.), en cuanto a los sectores y ramas de actividad donde trabajan unos y otras, o en relación a las formas de contratación más habituales entre los miembros de uno y otro sexo (Sajardo et al., 2009). Precisamente, parte del trabajo que aquí se presenta está dedicado a conocer la participación de las mujeres en la toma de decisiones en las EES, lo que permitirá profundizar en la segregación vertical; así como en su influencia en la gestión de estas empresas, concretamente de la RSE.

\subsection{Participación de la mujer en la toma de decisiones en las entidades de economía social}

En la actualidad no existen estadísticas fiables que permitan conocer la participación femenina en la toma de decisiones en las EES, independientemente de su forma jurídica. Sin

REVESCO No 105 - MONOGRÁFICO: La economía social y la igualdad de género -

ISSN: 1885-8031 - www.ucm.es/info/revesco 
embargo, si existen estudios sobre muestras concretas, como el de Sajardo et al. (2009) ${ }^{5}$. En este trabajo se reconoce que la participación media de las mujeres en puestos directivos de las empresas asciende al $31,6 \%$, alcanzando el $28,1 \%$ en las EES, el $34,4 \%$ en las sociedades limitadas, el 19,7\% en sociedades anónimas y el 18,8\% en otras formas jurídicas.

Asimismo, es fundamental conocer la participación de las mujeres en los diferentes órganos de toma de decisiones, como son la gerencia de la entidad y la presencia en el accionariado, pues los/as socios/as integran la Asamblea General e, incluso, el Consejo Rector. Además, es conveniente identificar su participación en la toma de decisiones en los distintos tipos de entidades que configuran las EES, pues aparentemente no existe homogeneidad en su distribución. En la Tabla 2 se exponen ambas informaciones.

\subsubsection{La participación femenina en la gerencia de las entidades de economía social}

La participación femenina en la gerencia de las EES asciende al 28,1\% (Sajardo et al., 2009), proporción que refleja la resistencia existente a la promoción de mujeres a directivas y, en consecuencia, la fuerte segregación vertical actual. Por ello, no se alcanza el nivel de paridad mínima de sexos establecido por la Ley Orgánica 3/2007 (alrededor del 40\%), generándose una injusta desigualdad en una sociedad como la actual, fundamentada en valores democráticos.

En las cooperativas de trabajo asociado casi se alcanza la paridad, pues aunque los hombres tienen una mayor presencia en la gerencia (60,2\%), las mujeres suponen el 39,2\% (COCETA, 2004). Investigaciones recientes muestran que las cooperativas son las que cuentan relativamente con más mujeres en sus órganos de gobierno en relación a otro tipo de organizaciones (Mateos, Escot y Gimeno, 2006; Esteban, 2007). Estas organizaciones poseen elementos de carácter personal, laboral y cultural distintos a los de otras empresas, que alientan la participación laboral y desarrollo profesional de las mujeres (Ribas y Sajardo, 2005). Sin embargo, la presencia masculina es superior a la femenina en los órganos de gobierno de las EES en su conjunto (Chaves, Ribas y Sajardo, 2005; Elio, 2006; Ribas, 2006; Sajardo et al., 2009).

${ }^{5}$ La muestra ha escogido las empresas socialmente responsables que han señalado tener un plan de igualdad.

REVESCO No 105 - MONOGRÁFICO: La economía social y la igualdad de género -

ISSN: 1885-8031 - www.ucm.es/info/revesco 
Tabla 2. Estudio Comparado de la Participación Femenina en los Puestos de Toma de Decisiones en las EES

\begin{tabular}{|c|c|c|c|c|c|c|}
\hline Autor del Estudio & $\begin{array}{l}\text { Berenguer, Castellví, } \\
\text { Cerver, Juan, Torcal y } \\
\text { De La Torre (1999) }\end{array}$ & $\begin{array}{l}\text { Romero y Pérez } \\
\text { (2000) }\end{array}$ & Ausin (2002) & $\begin{array}{c}\text { Institut Català de la } \\
\text { Dona i Dones dee la } \\
\text { Uniò de Pagesos } \\
(2003)\end{array}$ & $\begin{array}{c}\text { Asociación Navarra } \\
\text { de Empresas } \\
\text { Laborales (2003) }\end{array}$ & $\begin{array}{l}\text { Esteban, Gargallo y } \\
\text { Pérez (2010) }\end{array}$ \\
\hline Tipo de EES & $\begin{array}{l}\text { Cooperativas de } \\
\text { trabajo asociado }\end{array}$ & $\begin{array}{l}\text { Cooperativas de } \\
\text { trabajo asociado }\end{array}$ & $\begin{array}{l}\text { Cooperativas de } \\
\text { Enseñanza }\end{array}$ & Cooperativas Agrarias & Sociedades Laborales & Cooperativas \\
\hline $\begin{array}{l}\text { Comunidad } \\
\text { Autónoma }\end{array}$ & $\begin{array}{l}\text { Comunidad } \\
\text { Valenciana } \\
\end{array}$ & Andalucía & Extremadura & Cataluña & Navarra & Provincia Teruel \\
\hline & \multicolumn{6}{|c|}{ GERENCIA DE ENTIDADES DE ECONOMÍA SOCIAL } \\
\hline Presencia femenina & $\begin{array}{l}\text { 35,5\% Comité de } \\
\text { Dirección } \\
\text { 37,7\% puestos con } \\
\text { mando }\end{array}$ & $\begin{array}{c}25 \% \text { participan en la } \\
\text { gestión }\end{array}$ & $\begin{array}{c}12,1 \% \text { de las mujeres } \\
\text { son personal directivo } \\
3,7 \% \text { de las mujeres } \\
\text { son mandos } \\
\text { intermedios } \\
\text { Hombres: } 25,4 \% \text { y } \\
1,6 \% \text { respectivamente }\end{array}$ & $\begin{array}{l}\text { Dos mujeres ocupan } \\
\text { la presidencia, una la } \\
\text { secretaría y otra la } \\
\text { vicesecretaría. }\end{array}$ & $\begin{array}{l}\text { 11,9\% Consejos } \\
\text { Administración } \\
7,8 \% \text { de las mujeres } \\
\text { están cualificadas } \\
\text { como personal } \\
\text { directivo (frente al } \\
6,4 \% \text { de hombres) }\end{array}$ & $\begin{array}{c}20 \% \text { de las gerencias } \\
\text { son ocupadas por } \\
\text { mujeres }\end{array}$ \\
\hline $\begin{array}{c}\text { Otras } \\
\text { características: }\end{array}$ & $\begin{array}{c}\text { Participación } \\
\text { femenina aumenta } \\
\text { conforme lo hace el } \\
\text { tamaño del comité }\end{array}$ & & & $\begin{array}{c}\text { Mayor presencia de } \\
\text { mujeres en las } \\
\text { cooperativas más } \\
\text { antiguas }\end{array}$ & & \\
\hline \multirow{2}{*}{ Presencia femenina } & \multicolumn{6}{|c|}{ ACCIONARIADO DE ENTIDADES DE ECONOMÍA SOCIAL } \\
\hline & $\begin{array}{l}27,38 \% \text { Consejo } \\
\text { Rector }\end{array}$ & $\begin{array}{l}20 \% \text { Consejo Rector } \\
17,8 \% \text { Consejo Social }\end{array}$ & & & & $\begin{array}{c}17,09 \% \text { Consejo } \\
\text { Rector }\end{array}$ \\
\hline $\begin{array}{c}\text { Otras } \\
\text { características: }\end{array}$ & $\begin{array}{c}\text { Participación } \\
\text { femenina aumenta } \\
\text { conforme lo hace el } \\
\text { tamaño del Consejo }\end{array}$ & $\begin{array}{l}\text { Participación depende } \\
\text { de la proporción de } \\
\text { empleo femenino } \\
\text { existente }\end{array}$ & & $\begin{array}{c}84,5 \% \text { cooperativas } \\
\text { no tienen mujeres en } \\
\text { sus juntas. El } 63,2 \% \\
\text { de las que participan } \\
\text { son vocales }\end{array}$ & & $\begin{array}{c}0,97 \text { es la media de } \\
\text { mujeres por Consejo } \\
\text { Rector, superior al } \\
\text { resto de empresas } \\
\text { lucrativas }\end{array}$ \\
\hline
\end{tabular}

REVESCO Nº 105 - MONOGRÁFICO: La economía social y la igualdad de género -

ISSN: 1885-8031 - www.ucm.es/info/revesco 
Pese a esta realidad, en un $87,9 \%$ de los casos existe la opinión de que las cooperativas facilitan la incorporación de las mujeres a puestos directivos. Los mecanismos utilizados para tal fin son la participación en la toma de decisiones $(43,2 \%)$, la promoción interna $(22,2 \%)$, la formación (21,5\%) y la discriminación positiva (5\%), entre otras (COCETA, 2004).

Dentro del territorio nacional se han realizado múltiples estudios que analizan la presencia de la mujer en los órganos de decisión de las diferentes figuras jurídicas que se integran en la EES. Sus principales aportaciones aparecen expuestas en la Tabla 2. En resumen, el porcentaje de mujeres que participan en los órganos de dirección y gestión de las EES no se corresponde con la proporción de mujeres que trabajan en estas empresas, lo cual indica una mayor presencia de hombres en los puestos de más responsabilidad y toma de decisiones y, por lo tanto, la existencia de segregación vertical.

\subsubsection{La participación femenina en el accionariado de las entidades de economía social}

Para profundizar en la participación de hombres y mujeres en la toma de decisiones en las EES, también se pueden considerar los socios/as que integran la Asamblea General e, incluso, el Consejo Rector (Tabla 2).

Como se pone de manifiesto, el número de mujeres que participan en los consejos rectores no son un reflejo proporcional de las que potencialmente podrían ocupar dichos puestos, sobre todo en las sociedades cooperativas (Elio, 2006). No obstante, se observa una participación creciente de ellas conforme se incrementa la proporción de mujeres socias en la plantilla con un contrato societario (Elio, 2006).

Esta desigual participación de las mujeres en los distintos órganos de toma de decisiones en las EES se explica por la existencia del "techo de cristal" (Powell, 1991; Segerman-Peck, 1991; Davidson y Cooper, 1992), que incluye "las barreras artificiales e invisibles, creadas por prejuicios organizacionales y actitudinales, que impiden que muchas mujeres con elevada cualificación y capacidad personal y profesional puedan acceder a los niveles de dirección y responsabilidad más elevados y promocionar en ellos” (Wirth, 2001; Ramos, 2005). 
Los factores que justifican esta realidad se agrupan en tres ámbitos:

a) La socialización existente en nuestra sociedad, que determina trayectorias formativas y laborales de los/as jóvenes, incidiendo especialmente en su promoción, éxito y autolimitación profesional.

b) La dificultad para compatibilizar el espacio laboral y doméstico de las mujeres es un aspecto central del análisis del empleo femenino, derivado de la consideración de que la responsabilidad primera de las mujeres sigue siendo ocuparse del bienestar de la familia (Echebarria y Larrañaga, 2004), generando cuatro implicaciones directas sobre ellas: i) la brecha de género en el empleo y la distribución de las tareas de cuidado (Lázaro, Moltó y Sánchez, 2004); ii) el desarrollo de la "doble jornada", que complica el ejercicio profesional de las mujeres, exige mayor esfuerzo, una gran organización personal y conlleva una fuente extra de estrés, lo que reduce ocasionalmente su rendimiento; iii) su exclusión de la asunción de nuevas responsabilidades o de su desarrollo profesional, dado que tienen dificultad para acudir a cursos de formación o perfeccionamiento, y iv) su altísima participación en el trabajo a tiempo parcial, limitando su carrera profesional (Echebarria y Larrañaga, 2004; Lázaro et al., 2004). Esta situación se intensifica entre las directivas, ya que su trabajo se ha estructurado de forma tradicional, lo que exige disponer de un sistema de apoyo a tiempo total que las respalde desde el hogar (Echebarria y Larrañaga, 2004).

c) La cultura organizativa androcéntrica y patriarcal que favorece relaciones laborales de género asimétricas (Ramos, Barberá y Sarrió, 2003), donde los puestos de responsabilidad están asociados a características "masculinas" (Fernández, López, Maeztu y Martín, 2010), las cuales se vinculan con el éxito directivo empresarial. Este último factor es contrario a los postulados de las EES (basados en la igualdad, equidad, solidaridad, democracia, flexibilidad laboral, formación y capacitación), sin embargo está presente en estas firmas porque no son impermeables al entorno en el que se desenvuelven, de forma que reproducen los factores culturales y estereotipos de género capaces de determinar la segregación ocupacional horizontal y vertical (Teorías Feministas y Sociosexuales) (Ribas, 2010). Otras teorías relacionadas con la desigualdad de género, como la del Capital Humano, Nueva Economía de Familia, Segmentación de Mercados o la Teoría Institucionalista no justifican esta realidad por los valores característicos de la economía social (Ribas y Sajardo, 2004; Ribas, 2010).

REVESCO N 105 - MONOGRÁFICO: La economía social y la igualdad de género -

ISSN: 1885-8031 - www.ucm.es/info/revesco 
Con independencia de la segregación vertical que sufren las mujeres, es importante conocer su estilo directivo y si éste se diferencia del de sus colegas varones, aspectos que se abordan en el siguiente apartado.

\section{EL ESTILO DIRECTIVO DE LAS MUJERES}

Como ya se ha dejado entrever, cualquier organización requiere de un estilo directivo impregnado tanto de los valores masculinos como de los femeninos. Es importante que no se desaproveche el aporte que las mujeres altamente cualificadas pueden realizar a las empresas, instituciones públicas y EES. Por tanto, se hace necesario introducir un enfoque de diversidad de género en el mundo empresarial.

Según Loden (1987) existe un estilo de dirección femenino diferente al modelo tradicional de dirección masculina. El estilo de dirección de las mujeres se conoce como femenino-natural (Loden, 1987; Helgesen, 1990), y se caracteriza porque se basa tanto en lo racional como en lo emocional. En consecuencia, en la toma de decisiones influyen tanto los datos básicos como los sentimientos, y en la resolución de conflictos predomina el consenso, buscando alternativas en las que todos ganen y nadie tenga que perder (Ramos et al., 2003).

El estilo básico de las mujeres directivas se corresponde con una mayor orientación a las necesidades de las personas, lo que fomenta la cooperación, transmitiendo la importancia del trabajo en equipo y del desarrollo individual como meta para conseguir los logros organizacionales. Las mujeres tienen una mayor aptitud para mantener unas relaciones personales más estrechas con los demás, basadas en la comunicación y la relación interpersonal. Además, anteponen las necesidades de los demás y subordinan los progresos personales a corto plazo en favor de la mejora de la salud de la organización a largo plazo, de la que dependen tanto ellas como sus colaboradores. Asimismo, su estilo de dirección se caracteriza por un control reducido, comprensión, colaboración y niveles altos de rendimiento, teniendo como objetivo básico el logro de la calidad (Ramos et al., 2003).

REVESCO No 105 - MONOGRÁFICO: La economía social y la igualdad de género -

ISSN: 1885-8031 - www.ucm.es/info/revesco 
Sin embargo, el objetivo básico del estilo directivo masculino es sustancialmente diferente al femenino, pues está orientado a la consecución del éxito o el triunfo a través de la tarea, caracterizado por el poder concentrado en la posición jerárquica y donde impera la autoridad formal, que reúne la iniciativa, la organización y el control de comportamientos respecto a ciertas pautas (Redondo y Jimeno, 2008).

Tradicionalmente se han realizado estudios empíricos que comparan a directivos y directivas. Barberá, Ramos y Sarrió (2000) exponen los resultados de sus investigaciones en este ámbito, de forma que para analizar las diferencias de comportamientos estudian separadamente las características individuales, las opiniones de los subordinados y su nivel de satisfacción con el equipo de trabajo.

Las características individuales han considerado dos aspectos fundamentales: "el nivel de compromiso personal" del directivo/a con la organización laboral, y "la eficacia en la acción directiva”. En cuanto al nivel de compromiso individual no parecen diferir mujeres y hombres de modo significativo, fundamentándose las principales diferencias en aspectos contextuales, vinculados a factores de tipo personal (edad, nivel de formación, entre otros) y fundamentalmente a responsabilidades familiares (vivir sólo o en pareja, ser padres, o tener personas dependientes o no).

La eficacia en la acción directiva ha sido analizada en tres dimensiones específicas: a) la dirección orientada a la tarea, definida como el grado en que el directivo/a impulsa, organiza, define y controla la actividad laboral; b) el liderazgo interpersonal entendido como el grado en que el directivo/a se centra en el bienestar físico y psicológico de su equipo; y c) el carácter democrático/autocrático del liderazgo, que hace referencia al nivel en que el directivo/a estimula o no la participación del equipo en el proceso de toma de decisiones.

Los resultados empíricos concluyen que mujeres y hombres no parecen diferir, de forma significativa, en su mayor o menor eficacia como directivos. Si atendemos a las tres dimensiones consideradas, se observa que: a) no existe evidencia que la dirección orientada a la tarea proporcione resultados favorables a los hombres, como se presupone, salvo si las pruebas se han realizado en un laboratorio; b) el liderazgo interpersonal consigue mejores

REVESCO No 105 - MONOGRÁFICO: La economía social y la igualdad de género -

ISSN: 1885-8031 - www.ucm.es/info/revesco 
resultados para las mujeres, bajo pruebas de laboratorio, y c) el carácter democrático/autocrático del liderazgo si ofrece diferencias más acentuadas, de forma que las mujeres suelen mostrar formas más participativas y democráticas, resultado que se mantiene tanto en trabajos experimentales como en investigaciones de campo (Maher, 1997; Barberá et al., 2000). A nivel agregado, las diferencias observadas en las dimensiones parciales del comportamiento parecen compensarse, estando mejor posicionados en algunas dimensiones los hombres y en otras las mujeres.

Las opiniones de los subordinados respecto de sus jefes reales, varones o mujeres, no presentan diferencias significativas entre directivas y directivos. En igual sentido, su nivel de satisfacción con el equipo de trabajo tampoco muestra diferencias significativas entre unas y otros.

Otra investigación empírica más reciente es la desarrollada por Berenguer et al. (2004) en el ámbito de las cooperativas valencianas. Estos autores encuentran diferencias entre el estilo directivo femenino y masculino en la gestión del tiempo, pero no en la dimensión estratégico-analítica y en la gestión de la presión en el trabajo. Los resultados demuestran, por un lado, que no existen claras diferencias entre ambos estilos directivos, y por otro, que el hecho de que la mujer directiva tenga menos tiempo libre justifica que gestiona mejor su tiempo de trabajo.

En resumen, estos resultados refuerzan la tesis central de que los estereotipos de género no influyen en el estilo de dirección de mujeres y hombres, ya que tienden a disminuir cuando se hace referencia a personas concretas, en lugar de pensar en representaciones abstractas de la categoría "mujer" o "hombre".

De lo expuesto con relación a las características de los estilos directivos de hombres y mujeres se podría inferir, a priori, que el femenino, en la medida que está más orientado a las necesidades de las personas, podría ser más proclive a la puesta en marcha de políticas de RSE dirigidas a satisfacer las expectativas de los diferentes grupos de interés. Sin embargo, esta apreciación se puede ver contrarestada por el hecho de que, como se acaba de indicar, los diferentes estilos directivos y de liderazgo que mujeres y hombres desarrollan no parecen

REVESCO No 105 - MONOGRÁFICO: La economía social y la igualdad de género -

ISSN: 1885-8031 - www.ucm.es/info/revesco 
influir de forma significativa en la forma de dirigir y gestionar las organizaciones. Para profundizar en esta problemática, y ante la falta de estudios que la aborden, el presente trabajo incorpora un estudio empírico en el que, de forma exploratoria y en el ámbito de las EES, se analiza la influencia del género en la RSE de estas organizaciones, motivo por el que a continuación se exponen los fundamentos teóricos de este concepto.

\section{FUNDAMENTOS TEÓRICOS DE LA RESPONSABILIDAD SOCIAL EMPRESARIAL (RSE)}

De la revisión de las diferentes definiciones (Tabla 3) que sobre la RSE se han efectuado a lo largo de las últimas décadas se deducen tres características asociadas a este concepto (Marín, Arcas y Cortés, 2010). La primera es la existencia para la empresa de obligaciones que van más allá de sus responsabilidades económicas. La segunda, que la RSE conlleva unos principios básicos que deben permanecer en la empresa con el tiempo, y que deben orientar su marcha y su comportamiento, por lo que se debe situar a nivel estratégico. Por último, la tercera se refiere a que la empresa no sólo debe atender las demandas de sus accionistas sino la de todos los grupos de interés que están relacionados con la misma.

Tabla 3. Definiciones de RSE

\begin{tabular}{|c|c|l|}
\hline Autor & Año & \multicolumn{1}{c|}{ Definición de RSE } \\
\hline Davis & 1960 & $\begin{array}{l}\text { Las decisiones y las acciones tomadas por los empresarios que están, al menos en parte, más } \\
\text { allá de su interés económico o técnico. }\end{array}$ \\
\hline Carroll & 1979 & $\begin{array}{l}\text { La responsabilidad social es la forma en que la empresa da respuesta a las expectativas, } \\
\text { económicas, legales, éticas o discrecionales que la sociedad tiene sobre las organizaciones. }\end{array}$ \\
\hline Epstein & 1992 & $\begin{array}{l}\text { Se basa principalmente en lograr resultados positivos en las decisiones organizacionales que } \\
\text { conciernen a temas específicos o problemas que tienen más efectos positivos que negativos } \\
\text { sobre los grupos de interés de la empresa. }\end{array}$ \\
\hline $\begin{array}{c}\text { Comisión } \\
\text { Europea }\end{array}$ & 2001 & $\begin{array}{l}\text { La integración voluntaria, por parte de las empresas, de las preocupaciones sociales y } \\
\text { medioambientales en sus operaciones comerciales y sus relaciones con sus interlocutores. }\end{array}$ \\
\hline $\begin{array}{c}\text { Lafuente } \text { et al. } \\
\text { La }\end{array}$ & 2003 & $\begin{array}{l}\text { La adopción de criterios de RSC en la gestión empresarial entraña la formalización de } \\
\text { políticas y sistemas en los ámbitos económico, social y medioambiental, la transparencia } \\
\text { informativa respecto a los resultados alcanzados en tales ámbitos y el escrutinio externo de } \\
\text { los mismos. }\end{array}$ \\
\hline $\begin{array}{c}\text { De la Cuesta y } \\
\text { Valor }\end{array}$ & 2003 & $\begin{array}{l}\text { El reconocimiento e integración en sus operaciones por parte de las empresas, de las } \\
\text { preocupaciones sociales y medioambientales, dando lugar a prácticas empresariales que } \\
\text { satisfagan dichas preocupaciones y configuren sus relaciones con sus interlocutores. }\end{array}$ \\
\hline AECA & 2004 & $\begin{array}{l}\text { El compromiso voluntario de las empresas con el desarrollo de la sociedad y la preservación } \\
\text { del medio ambiente, desde su composición social y un comportamiento responsable hacia }\end{array}$ \\
\hline
\end{tabular}

REVESCO No 105 - MONOGRÁFICO: La economía social y la igualdad de género -

ISSN: 1885-8031 - www.ucm.es/info/revesco 


\begin{tabular}{|c|c|l|}
\hline & & las empresas y grupos sociales con quien interactúa. \\
\hline $\begin{array}{c}\text { Ministerio de } \\
\text { Trabajo y } \\
\text { Asuntos Sociales }\end{array}$ & 2007 & $\begin{array}{l}\text { La Responsabilidad Social de la Empresa es, además del cumplimiento estricto de las } \\
\text { obligaciones legales vigentes, la integración voluntaria en su gobierno y gestión, en su } \\
\text { estrategia, políticas y procedimientos, de las preocupaciones sociales, laborales, medio } \\
\text { ambientales y de respeto a los derechos humanos que surgen de la relación y el diálogo } \\
\text { transparentes con sus grupos de interés, responsabilizándose así de las consecuencias y los } \\
\text { impactos que se derivan de sus acciones. }\end{array}$ \\
\hline
\end{tabular}

Fuente: Marín et al. (2010).

Por lo tanto, la RSE se refiere a cómo las empresas son gestionadas para satisfacer las expectativas de sus diferentes grupos de interés o "stakeholders" (empleados, clientes, socios, accionistas, proveedores comunidad y medio ambiente). Esta gestión de la empresa que respeta a todos sus grupos de interés supone un planteamiento de tipo estratégico que afecta a la toma de decisiones y a las operaciones de toda la organización, creando valor en el largo plazo y contribuyendo significativamente a la obtención de ventajas competitivas duraderas (AECA, 2004).

En cuanto a las dimensiones de la RSE, en la literatura aparecen varias aportaciones con enfoques diferentes, siendo las más aceptadas las tres dimensiones a las que hacen referencia el Libro Verde "Fomentar un marco europeo para la responsabilidad social de las empresas" (Comisión de las Comunidades Europeas, 2001) y De la Cuesta y Valor (2003). Esta clasificación se alinea con la propuesta que, desde su origen, formula el Glogal Reporting Inititative en las distintas versiones de sus guías para la elaboración de reportes o memorias de RSE, a saber:

Responsabilidad económica. Esta dimensión implica la creación de valor para el accionista o propietario; para el cliente por medio de la atención de sus demandas; para los proveedores pagando precios justos por sus productos o servicios, y para los empleados protegiendo y generando empleo, en base a un sistema de justicia salarial, proporcionando beneficios sociales, formación, estabilidad y motivación.

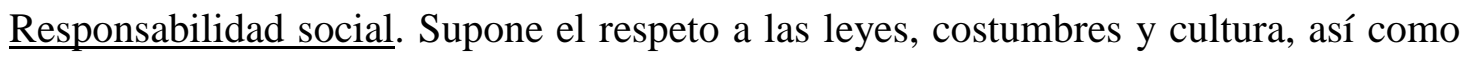
implicarse en el ámbito político de su entorno. Los dos primeros aspectos requieren que la empresa acepte los estándares legales y socioculturales de la sociedad en la que operan, mientras que el último supone un papel más activo de la empresa, adoptando iniciativas que mejoran el bienestar general de la sociedad.

REVESCO No 105 - MONOGRÁFICO: La economía social y la igualdad de género -

ISSN: 1885-8031 - www.ucm.es/info/revesco 


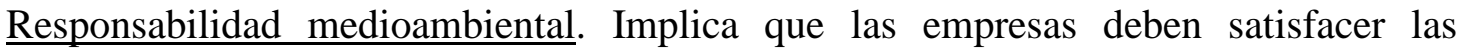
necesidades actuales de sus grupos de interés sin comprometer las de las generaciones futuras, contribuyendo así al desarrollo sostenible.

A partir de estas tres dimensiones de la RSE, la RSE se puede definir como "las acciones que llevan a cabo las organizaciones en materia económica, social y medioambiental para responder a las expectativas de sus grupos de interés, tanto internos como externos, y, de esta forma alcanzar ventajas competitivas" (Figura 2).

Por otra parte, diversos autores coinciden al señalar que las EES, entre las que destacan las cooperativas y sociedades laborales, presentan una serie de singularidades que propician y facilitan la adopción de comportamientos propios de la RSE (Arcas y Briones, 2009). En la misma línea se manifiesta la Confederación Empresarial Española de la Economía Social cuando sostiene que "no es ajeno a la Economía Social la RSE como estrategia empresarial, ya que entre los valores de las empresas de Economía Social y los valores que promueve la RSE existen coincidencias significativas" (CEPES, 2009).

REVESCO No 105 - MONOGRÁFICO: La economía social y la igualdad de género ISSN: 1885-8031 - www.ucm.es/info/revesco 


\section{Figura 2. Dimensiones de la RSE}

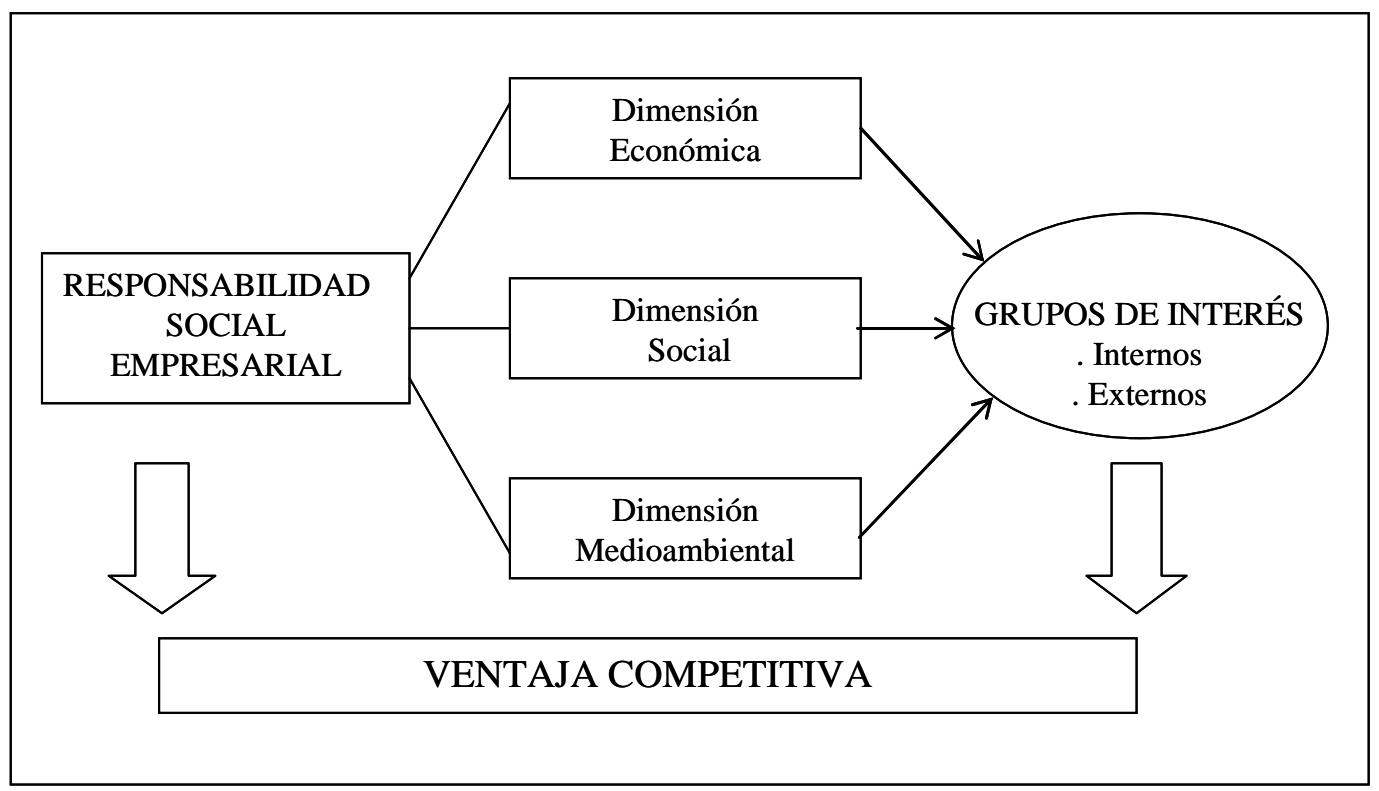

Fuente: Elaboración propia.

El paralelismo entre los valores y principios del cooperativismo y la RSE ha sido establecido por autores como Server y Capó (2009) o Arcas y Briones (2009), tal y como aparece en la Tabla 4.

Tabla 4. Paralelismo entre los Valores y Principios del Cooperativismo y la RSE.

\begin{tabular}{|c|c|}
\hline COOPERATIVISMO & RSE \\
\hline $\begin{array}{c}\text { Ayuda mutua, responsabilidad, democracia, } \\
\text { igualdad, equidad, solidaridad, honestidad, } \\
\text { transparencia, responsabilidad social y } \\
\text { preocupación por los demás. }\end{array}$ & Ética, honestidad, respeto a los derechos humanos y \\
& \begin{tabular}{c} 
transparencia \\
\hline
\end{tabular} \\
\hline Adhesión abierta y voluntaria & Principios \\
\hline Control democrático de los socios & Integración \\
\hline Educación, Entrenamiento e Información & Participación \\
\hline Cooperación entre cooperativas & Integración y extensión \\
\hline Compromiso con la comunidad & Sostenibilidad \\
\hline
\end{tabular}

Fuente: Arcas y Briones (2009).

REVESCO No 105 - MONOGRÁFICO: La economía social y la igualdad de género -

ISSN: 1885-8031 - www.ucm.es/info/revesco 


\section{METODOLOGÍA DE LA INVESTIGACIÓN}

\subsection{Muestra y recogida de datos}

La información necesaria para la elaboración de este trabajo fue obtenida a través de un cuestionario dirigido a presidentes o gerentes de empresas españolas de la Economía Social. El cuestionario traslada el objetivo de la investigación a preguntas concretas, intentando conocer el comportamiento de cada empresa en relación con las tres dimensiones de la Responsabilidad Social Empresarial: económica, medioambiental y social.

Para obtener la información de contacto (direcciones de correo electrónico) se accedió a las distintas bases de datos de las Organizaciones Representativas de las empresas de economía social españolas, tales como: La Confederación de Cooperativas de Trabajo Asociado de España, La Confederación Empresarial de Sociedades Anónimas Laborales de España, Cooperativas Agro-alimentarias, así como a distintas bases de datos de las Organizaciones Representativas de las Comunidades Autónomas que cuentan con directorios empresariales.

El cuestionario fue enviado vía correo electrónico, por ser éste el medio que brinda mayores posibilidades de cobertura en un periodo limitado de tiempo, acompañado de una carta de presentación dirigida a los presidentes o gerente. La encuesta se distribuyo a un total de 2.500 empresas. Tras finalizar el proceso de lanzamiento de la encuesta a las 2.500 empresas se recibieron debidamente cumplimentados 134 cuestionarios $(5,4 \%)$, por lo que la encuesta quedo formada por $134 \mathrm{EES}$.

El cuestionario también incluye una serie de preguntas relativas a las empresas de economía social que constituyen la muestra, así como de sus presidentes o gerentes, lo que nos ha permitido realizar la caracterización que aparece en la Tabla 5.

Tabla 5. Caracterización de la Muestra

\begin{tabular}{|l|l|c|}
\hline \multicolumn{2}{|c|}{ Característica } & Media \\
\hline \multirow{2}{*}{ Tipo de entidad (\%) } & Cooperativa Agraria & 19,1 \\
\cline { 2 - 3 } & Cooperativa de Trabajo Asociado & 45,6 \\
\hline
\end{tabular}

REVESCO No 105 - MONOGRÁFICO: La economía social y la igualdad de género ISSN: 1885-8031 - www.ucm.es/info/revesco 


\begin{tabular}{|c|c|c|}
\hline & Sociedad Laboral & 35,3 \\
\hline \multicolumn{2}{|l|}{ Año de constitución } & 1995 \\
\hline \multicolumn{2}{|l|}{ Número de socios } & 69 \\
\hline \multicolumn{2}{|l|}{$\%$ de socios hombres } & 79 \\
\hline \multicolumn{2}{|l|}{$\%$ de socios mujeres } & 29 \\
\hline \multicolumn{2}{|l|}{ Facturación en 2008 (Millones de euros) } & 10,6 \\
\hline \multicolumn{2}{|l|}{$\%$ de mujeres trabajadoras } & 42,9 \\
\hline \multicolumn{2}{|l|}{ Edad del presidente/gerente } & 44 \\
\hline \multicolumn{2}{|l|}{$\%$ de mujeres presidentes/gerentes } & 22,7 \\
\hline \multirow{4}{*}{ Nivel de estudios del gerente (\%) } & Estudios primarios & 24,3 \\
\hline & Bachiller & 16,9 \\
\hline & Formación profesional & 11,0 \\
\hline & Universitarios & 47,8 \\
\hline
\end{tabular}

Fuente: Elaboración Propia.

\subsection{Desarrollo de medidas}

Para medir los aspectos de genero se utilizaron dos variables métricas (porcentaje de mujeres trabajadoras y porcentaje de mujeres socias) y una variable categórica (sexo: $0=$ hombre y $1=$ mujer).

Las opiniones y juicios de valoración relacionados con las tres dimensiones de la RSE, puesto que no es adecuado medirlos de forma directa, para su medición se desarrollaron escalas multi-ítem de clasificación por categorías de 0 (nada de acuerdo) a 10 puntos (totalmente de acuerdo), ampliamente aceptadas por los investigadores para su evaluación (Grande y Abascal, 2007). De esta forma, el valor considerado para cada una de las dimensiones de la RSE ha sido la media aritmética de los ítemes que integran su escala de medida, y el de la RSE la media aritmética de sus tres dimensiones.

Para determinar la bondad de las escalas utilizadas comprobamos si éstas satisfacen los criterios de fiabilidad y validez (convergente y discriminante). Para comprobar la fiabilidad nos basamos en el coeficiente Alpha de Cronbach, cuyo valor óptimo dependerá del propósito de la investigación (Churchill, 1979). Así, para las primeras etapas de cualquier investigación, entre 0,5 y 0,6 puede ser suficiente.

REVESCO No 105 - MONOGRÁFICO: La economía social y la igualdad de género -

ISSN: 1885-8031 - www.ucm.es/info/revesco 
Para aproximarnos a la validez convergente realizamos un análisis factorial con los ítemes de cada una de las variables, eliminando aquellos que no saturan en el factor. Por último, la validez discriminante se contrasta realizando un análisis factorial con todos los ítemes que satisfacen el resto de las condiciones de fiabilidad y validez. Así, podemos comprobar que los ítemes de escalas diferentes no pesan en un mismo factor o dimensión, como característica de la existencia de validez discriminante. De esta forma, si saturan en la dimensión propuesta y el análisis presenta una bondad adecuada, estaremos en condiciones de afirmar que hay validez discriminante.

En la Tabla 6 aparecen los ítemes utilizados para medir las dimensiones económica, medioambiental y social que integran el modelo una vez depuradas las escalas prescindiendo de aquellos ítemes que no satisfacen los criterios mínimos indicados. En ella también se incluyen el valor del Alpha de Cronbach ( $\alpha$ ), el índice KMO del análisis factorial realizado y las cargas factoriales de cada ítem en la variable que presentan una mayor carga, confirmando todos estos valores la bondad de las escalas finalmente utilizadas.

Tabla 6. Medidas de las Variables

\begin{tabular}{|c|c|c|c|c|c|c|c|}
\hline Variable & Ítemes & Media & $\alpha$ & $\mathbf{F}_{1}$ & $\mathbf{F}_{2}$ & $\mathbf{F}_{3}$ & KMO \\
\hline \multirow{10}{*}{ 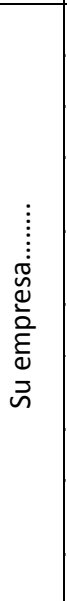 } & Se lleva con métodos de gestión modernos & 7,21 & \multirow{10}{*}{0,880} & 0,685 & & & \multirow{17}{*}{0,878} \\
\hline & Tiene planificación a largo plazo & 6,97 & & 0,688 & & & \\
\hline & Tiene presupuesto de ingresos y gastos & 7,43 & & 0,570 & & & \\
\hline & $\begin{array}{l}\text { Tiene perfectamente identificada y estudiada quien es su } \\
\text { competencia }\end{array}$ & 7,12 & & 0,543 & & & \\
\hline & $\begin{array}{l}\text { Establece mecanismos de aseguramiento de la calidad y de } \\
\text { mejora continua en todos los ámbitos de su actividad }\end{array}$ & 6,94 & & 0,655 & & & \\
\hline & Vende sus productos dando mucha información a los clientes & 7,71 & & 0,661 & & & \\
\hline & $\begin{array}{l}\text { Vende sus productos dando información de calidad a los } \\
\text { clientes }\end{array}$ & 7,84 & & 0,648 & & & \\
\hline & Destina recursos para innovar en su actividad & 7,31 & & 0,717 & & & \\
\hline & $\begin{array}{l}\text { Obtiene una parte importante de su facturación de actividades } \\
\text { innovadoras }\end{array}$ & 5,71 & & 0,650 & & & \\
\hline & Está preocupada por innovar nuevos productos, procesos, etc. & 7,41 & & 0,735 & & & \\
\hline \multirow{7}{*}{ 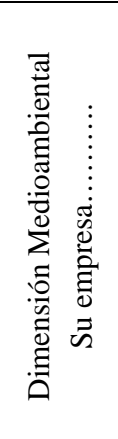 } & $\begin{array}{l}\text { Dedica recursos a reducir los posibles impactos de su } \\
\text { actividad sobre la naturaleza }\end{array}$ & 6,33 & \multirow{7}{*}{0,950} & & 0,697 & & \\
\hline & $\begin{array}{l}\text { Realiza un seguimiento de los residuos que genera y los tiene } \\
\text { cuantificados }\end{array}$ & 6,16 & & & 0,680 & & \\
\hline & Adopta medidas para mejorar la gestión de los residuos & 6,31 & & & 0,721 & & \\
\hline & Controla el consumo anual de agua & 5,72 & & & 0,721 & & \\
\hline & $\begin{array}{l}\text { Ha implantado o va a implantar un sistema de reutilización de } \\
\text { sus aguas residuales }\end{array}$ & 2,46 & & & 0,630 & & \\
\hline & $\begin{array}{l}\text { Adopta medidas para mejorar la gestión del agua (eficiencia, } \\
\text { etc.) }\end{array}$ & 4,80 & & & 0,673 & & \\
\hline & Tiene mecanismos para favorecer el ahorro energético & 5,93 & & & 0,670 & & \\
\hline
\end{tabular}

REVESCO No 105 - MONOGRÁFICO: La economía social y la igualdad de género -

ISSN: 1885-8031 - www.ucm.es/info/revesco 


\begin{tabular}{|c|c|c|c|c|c|c|}
\hline & & $\begin{array}{l}\text { Tiene indicadores de medida de la energía que le permiten } \\
\text { analizar resultados y fijar objetivos de mejora }\end{array}$ & 4,09 & & 0,671 & \\
\hline & & $\begin{array}{l}\text { Ha invertido o tiene intención de invertir en energías } \\
\text { renovables }\end{array}$ & 4,53 & & 0,695 & \\
\hline & & Minimiza la emisión de contaminantes a la atmósfera & 5,35 & & 0,812 & \\
\hline & & $\begin{array}{l}\text { Controla las emisiones de gases de efecto invernadero (CO2, } \\
\text { etc.) }\end{array}$ & 4,27 & & 0,860 & \\
\hline & & Lleva un control de los gases que pueden deteriorar la salud & 3,90 & & 0,842 & \\
\hline & & Reduce la contaminación lumínica & 5,77 & & 0,632 & \\
\hline & & $\begin{array}{l}\text { Evita la contaminación y la erosión de suelo donde desarrolla } \\
\text { su actividad }\end{array}$ & 5,41 & & 0,730 & \\
\hline & & Controla y mide los vertidos de todo tipo que hace & 5,84 & & 0,775 & \\
\hline & & $\begin{array}{l}\text { Fomenta la formación de sus trabajadores en los temas } \\
\text { medioambientales }\end{array}$ & 5,99 & & 0,654 & \\
\hline & & Invierte en formación medioambiental de sus trabajadores & 5,43 & & 0,620 & \\
\hline & & Evita cualquier impacto negativo sobre el territorio & 6,88 & & 0,554 & \\
\hline & & Trabaja en la protección y restauración de espacios naturales & 4,46 & & 0,518 & \\
\hline & & $\begin{array}{l}\text { Impulsa que haya democracia interna de forma que los socios } \\
\text { puedan opinar más allá de lo que marcan sus estatutos }\end{array}$ & 8,38 & & & 0,657 \\
\hline & & Estimula la participación de los socios en la Asamblea General & 8,67 & & & 0,682 \\
\hline 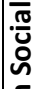 & $\vdots$ & $\begin{array}{l}\text { Facilita a los socios información sobre cómo marcha la } \\
\text { sociedad laboral }\end{array}$ & 9,13 & & & 0,889 \\
\hline$: \frac{̃}{\mathrm{u}}$ & है & $\begin{array}{l}\text { Tiene en cuenta las opiniones que los socios dicen en la } \\
\text { Asamblea }\end{array}$ & 9,17 & 0,876 & & 0,839 \\
\hline & $\stackrel{\frac{\omega}{3}}{\sim}$ & Facilita a los socios toda la información que solicitan & 9,17 & & & 0,784 \\
\hline & & $\begin{array}{l}\text { Es absolutamente transparente en las cuentas con todos sus } \\
\text { socios }\end{array}$ & 9,29 & & & 0,766 \\
\hline & & Fomenta la estabilidad laboral de la plantilla & 8,74 & & & 0,555 \\
\hline
\end{tabular}

Fuente: Elaboración Propia. $F_{1}=$ Carga factorial en la variable dimensión económica, $F_{2}=$ Carga factorial en la variable dimensión medioambiental, $F_{3}=$ Carga factorial en la variable dimensión social.

\section{RESULTADOS}

\subsection{Participación de las mujeres en las empresas de economía social}

\subsubsection{En el total de los trabajadores}

El análisis de los datos obtenidos de la muestra revela que, de media, las mujeres suponen el $42,9 \%$ del total de los trabajadores de las cooperativas y sociedades laborales (51,7\% en el caso de las cooperativas y $26,8 \%$ en el de las sociedades laborales). Si se comparan estos porcentajes con los aportados anteriormente procedentes de las estadísticas del Ministerio de Trabajo e Inmigración, correspondiente a 2009, se observa que se encuentran ligeramente por encima en el caso de las cooperativas $(46,8 \%)$ y bastante por debajo en las sociedades laborales $(53,2 \%)$. Por otra parte, se confirma que, aunque la

REVESCO No 105 - MONOGRÁFICO: La economía social y la igualdad de género -

ISSN: 1885-8031 - www.ucm.es/info/revesco 
participación de las mujeres en las empresas de la Economía Social supera a la del resto de empresas, todavía no es totalmente paritaria.

\subsubsection{En la toma de decisiones: socios y gerencia}

Los resultados obtenidos se aproximan al estudio comentado anteriormente de Sajardo et al. (2009), quienes señalan que el porcentaje de participación de mujeres en puestos de dirección alcanza un $28,1 \%$. Del análisis de la muestra objeto de este estudio se deduce que en sólo el $23 \%$ de las empresas (29\% en cooperativas y $15 \%$ en sociedades laborales) la gerencia es ocupada por una mujer, valor que está muy alejado de la paridad mínima de sexos establecida por la Ley Orgánica 3/2007 (alrededor del 40\%).

En cuanto a la distribución de género entre los socios/as de las EES que integran la muestra, quienes también pueden participar en la toma de decisiones de las empresas a través de su pertenencia a la Asamblea General e, incluso, el Consejo Rector, se observa que esta participación de las mujeres es inferior a la representatividad de las trabajadoras, pero supera a la de las gerentes. En concreto, las mujeres socias sólo suponen el $29,5 \%(36,1 \%$ en cooperativas y $19,6 \%$ en sociedades laborales).

\subsection{Grado de RSE}

Los resultados obtenidos demuestran que las empresas de Economía Social analizadas presentan valoraciones positivas (superiores a 5 puntos sobre 10) tanto para la $\operatorname{RSE}(7,1$ puntos) como para cada una de sus tres dimensiones. Además, la prueba T para muestras relacionadas pone de manifiesto que la dimensión más valorada es la social (8,9 puntos), seguida de la económica (7,2 puntos) y la medioambiental (5,2 puntos). De esta forma se confirman las afirmaciones teóricas que postulan la adopción por las cooperativas y las sociedades laborales de los comportamientos propios de la RSE, en línea también con los escasos trabajos empíricos que existen (Arcas y Briones, 2009; Sajardo et al., 2009).

REVESCO No 105 - MONOGRÁFICO: La economía social y la igualdad de género -

ISSN: 1885-8031 - www.ucm.es/info/revesco 


\subsection{Influencia del género en la RSE}

Para conocer la posible influencia del género sobre la RSE y cada una de sus dimensiones se ha utilizado el método de regresión mediante mínimos cuadrados ordinarios, considerando la RSE y sus dimensiones como variables dependientes y las medidas de genero (\% de mujeres trabajadoras, \% de mujeres socias y sexo del gerente) como variables independientes. Debido a la elevada correlación que en la muestra se ha comprobado que existe entre las tres variables de género, se ha optado por no incorporarlas en la misma regresión. Concretamente, se han utilizado regresiones jerárquicas utilizando en todas ellas como variables independientes una variable control (la facturación de la empresa como medida de su tamaño) y cada una de las tres variables de genero, comprobando la significatividad del cambio en el coeficiente de determinación lineal $\mathrm{R}^{2}$ con la adición de las variables de género a la variable control. La elección del tamaño de la empresa como variable control se debe a su elevada capacidad para explicar la RSE (Forética, 2008; Sajardo et al., 2009).

De esta forma, para cada una de las cuatro variables dependientes (RSE y sus dimensiones económica, medioambiental y social) y cada una de las variables de género (\% de mujeres trabajadoras, \% de mujeres socias y sexo del gerente) se estimaron dos modelos de regresión. En el primero (M.1) se introduce como variable independiente la variable control (facturación de la empresa), mientras que en el modelo 2 (M.2) se añade a la variable de control la variable de género considerada.

Los resultados obtenidos se presentan en las Tablas 7, 8 y 9. En ningún caso, el modelo (M.2) que incluye las variables de genero contribuye significativamente en la explicación de la RSE ni de sus dimensiones en mayor medida que lo hace el modelo 1 (M.1) que incluye como variable independiente el tamaño de la empresa. Este resultado se puede apreciar observando la no significatividad en el cambio de la $\mathrm{R}^{2}$ que presentan. Como consecuencia de estos resultados se puede concluir que, con independencia de la variable de género considerada, la mayor participación de las mujeres en la toma de decisiones de las empresas de economía social no afecta ni a la RSE medida en su conjunto ni a cada una de sus dimensiones (económica, medioambiental y social).

REVESCO No 105 - MONOGRÁFICO: La economía social y la igualdad de género -

ISSN: 1885-8031 - www.ucm.es/info/revesco 
Tabla 7. Resultados del Análisis de Regresión

\begin{tabular}{|c|c|c|c|c|c|c|c|c|}
\hline V. Dependiente & \multicolumn{2}{|c|}{ RSE } & \multicolumn{2}{|c|}{$\begin{array}{l}\text { Dimensión } \\
\text { Económica }\end{array}$} & \multicolumn{2}{|c|}{$\begin{array}{c}\text { Dimensión } \\
\text { Medioambiental }\end{array}$} & \multicolumn{2}{|c|}{$\begin{array}{c}\text { Dimensión } \\
\text { Social }\end{array}$} \\
\hline V. Independientes $\downarrow$ & M. 1 & M. 2 & M. 1 & M. 2 & M. 1 & M. 2 & M. 1 & M. 2 \\
\hline Tamaño (facturación en miles euros) &, $095^{\text {n.s. }}$ &, $094^{\text {n.s. }}$ & $135^{\text {n.s. }}$ &, $0132^{\text {n.s. }}$ & $103^{\text {n.s. }}$ & $0102^{\text {n.s. }}$ &,$- 076^{\text {n.s. }}$ &,$- 076^{\text {n.s. }}$ \\
\hline \% Mujeres trabajadoras & & $049^{\text {n.s. }}$ & & $100^{\text {n.s. }}$ & &, $012^{\text {n.s. }}$ & &, $002^{\text {n.s. }}$ \\
\hline $\mathrm{R}^{2}$ & 009 & 011 & 018 & 028 & ,011 & 011 & 006 & 006 \\
\hline Sig. cambio en $\mathrm{R}^{2}$ & ,331 & ,615 & , 165 & ,302 & ,293 & 905 & ,437 & ,981 \\
\hline
\end{tabular}

Tabla 8. Resultados del Análisis de Regresión

\begin{tabular}{|c|c|c|c|c|c|c|c|c|}
\hline V. Dependiente & \multicolumn{2}{|c|}{ RSE } & \multicolumn{2}{|c|}{$\begin{array}{l}\text { Dimensión } \\
\text { Económica }\end{array}$} & \multicolumn{2}{|c|}{$\begin{array}{c}\text { Dimensión } \\
\text { Medioambiental }\end{array}$} & \multicolumn{2}{|c|}{$\begin{array}{c}\text { Dimensión } \\
\text { Social }\end{array}$} \\
\hline V. Independientes $\downarrow$ & M. 1 & M. 2 & M. 1 & M. 2 & M. 1 & M. 2 & M. 1 & M. 2 \\
\hline Tamaño (facturación en miles euros) & $309^{\mathrm{b}}$ & $309^{\mathrm{b}}$ & $230^{\mathrm{c} .}$ &, $0230^{\mathrm{c}}$ & $299^{\mathrm{b}}$ &, $0299^{\mathrm{b} .}$ & $137^{\text {n.s. }}$ &, $137^{\text {n.s. }}$ \\
\hline \% Mujeres socios & &,$- 078^{\text {n.s. }}$ & &,$- 095^{\text {n.s. }}$ & &,$- 120^{\text {n.s. }}$ & & $126^{\text {n.s. }}$ \\
\hline $\mathrm{R}^{2}$ & 095 & ,102 & 053 & ,062 & ,089 & ,104 & ,019 & 035 \\
\hline Sig. cambio en $\mathrm{R}^{2}$ & ,002 & ,432 & 025 & ,354 & ,003 & ,229 & ,189 & ,223 \\
\hline
\end{tabular}

${ }^{\mathrm{a}} \mathrm{p}<, 001 ;{ }^{\mathrm{b}} \mathrm{p}<, 01 ;{ }^{\mathrm{c}} \mathrm{p}<, 05 ;$ n.s. $=$ no significativo.

Tabla 9. Resultados del análisis de regresión

\begin{tabular}{|c|c|c|c|c|c|c|c|c|}
\hline V. Dependiente & \multicolumn{2}{|c|}{ RSE } & \multicolumn{2}{|c|}{$\begin{array}{l}\text { Dimensión } \\
\text { Económica }\end{array}$} & \multicolumn{2}{|c|}{$\begin{array}{c}\text { Dimensión } \\
\text { Medioambiental }\end{array}$} & \multicolumn{2}{|c|}{$\begin{array}{c}\text { Dimensión } \\
\text { Social }\end{array}$} \\
\hline V. Independientes $\downarrow$ & M. 1 & M. 2 & M. 1 & M. 2 & M. 1 & M. 2 & M. 1 & M. 2 \\
\hline Tamaño (facturación en miles euros) &, $324^{\mathrm{b}}$ &, $324^{\mathrm{b}}$ & $277^{\mathrm{b}}$ & $275^{\mathrm{b}}$ & $294^{\mathrm{b}}$ &, $0296^{\text {b. }}$ &, $120^{\text {n.s. }}$ &, $117^{\text {n.s. }}$ \\
\hline Sexo & &,$- 078^{\text {n.s. }}$ & &, $051^{\mathrm{n} . \mathrm{s}}$ & &,$- 071^{\text {n.s. }}$ & &, $077^{\text {n.s. }}$ \\
\hline $\mathrm{R}^{2}$ &, 105 &, 105 & ,077 & ,079 & ,086 & ,091 & 014 &, 020 \\
\hline Sig. cambio en $\mathrm{R}^{2}$ & ,001 & ,999 & ,006 & ,611 & ,003 & ,473 & 243 & ,453 \\
\hline
\end{tabular}

${ }^{\mathrm{a}} \mathrm{p}<, 001 ;{ }^{\mathrm{b}} \mathrm{p}<, 01 ;{ }^{\mathrm{c}} \mathrm{p}<, 05 ;$ n.s. $=$ no significativo.

\section{CONCLUSIONES}

En la actualidad, la sociedad exige a las empresas compromisos que superan lo estrictamente económico y, cada vez más, se enmarcan en los ámbitos medioambiental y social, entre los que destacan los relacionados con la igualdad de género. Esto está provocando que las empresas en general, y las de economía social en particular, asuman este

REVESCO Nº 105 - MONOGRÁFICO: La economía social y la igualdad de género -

ISSN: 1885-8031 - www.ucm.es/info/revesco 
tipo de responsabilidades y adopten prácticas de RSE dirigidas a satisfacer las expectativas de los diferentes grupos de interés.

La igualdad de género y, por extensión, la RSE son conceptos inherentes a las EES, de manera que los principios que guían el funcionamiento de estas organizaciones (democracia, igualdad, equidad, solidaridad, etc.) guardan estrecha relación con el sentido y la filosofía de la RSE. Esto origina que las EES sean por naturaleza socialmente responsables, lo que les lleva a adoptar comportamientos propios de la RSE, entre los que destacan los relacionados con la igualdad de género.

Sin embargo, al igual que sucede en el conjunto de las empresas, las evidencias empíricas disponibles muestran que la presencia de las mujeres en la toma de decisiones de las EES es mucho más reducida que la de los hombres, lo que está provocando el desaprovechamiento del particular estilo directivo femenino. Esto confirma que las EES no son ajenas a los efectos de la segregación vertical, fundamentados en las Teorías Feministas y Sociosexuales.

Por otra parte, los trabajos existentes señalan que el estilo directivo femenino difiere del masculino, aunque la cultura empresarial y los estereotipos de género podrían estar impidiendo su diferenciación efectiva. No obstante, puesto que la RSE es un estilo de dirección directamente relacionado con los principios que guían la organización, cabe pensar que su gestión podría estar relacionada con el perfil de las personas que adoptan las decisiones, entre las que figura el sexo.

Con el objetivo de contrastar en el ámbito de las EES las observaciones anteriores relativas al grado de RSE e igualdad de género de estas organizaciones, así como la relación entre ambos conceptos, y ante la escasez de estudios que aborden esta problemática, se ha efectuado un estudio empírico exploratorio con la información obtenida de 134 entidades de economía social (cooperativas y sociedades laborales).

Los resultados obtenidos confirman que: a) las empresas de economía social analizadas presentan valoraciones elevadas (superiores a 5 puntos sobre 10) tanto para la RSE

REVESCO No 105 - MONOGRÁFICO: La economía social y la igualdad de género -

ISSN: 1885-8031 - www.ucm.es/info/revesco 
como para cada una de sus tres dimensiones, siendo la más valorada la social, seguida de la económica y la medioambiental; b) las mujeres suponen el 42,9\% del total de los trabajadores de las cooperativas y sociedades laborales, cumpliéndose por tanto la paridad mínima de sexos establecida por la Ley Orgánica 3/2007 (alrededor del 40\%), en cambio su participación en la toma de decisiones es muy inferior. En concreto, se observa que las mujeres socias sólo suponen el 29,5\%, siendo todavía inferior el porcentaje de mujeres que acceden a la gerencia (23\%), valores ambos muy alejados de la paridad mínima de sexos; y c) la mayor participación de las mujeres en la toma de decisiones de las EES no afecta ni a la RSE de estas organizaciones ni a cada una de sus dimensiones (económica, social y medioambiental).

Estos resultados avalan los obtenidos en los escasos trabajos existentes, de forma que las EES parece que no han superado la segregación vertical. Esta conclusión, opuesta a lo esperado atendiendo a los valores que guían a este tipo de organizaciones, contrarios a toda clase de discriminación, confirma, en línea con lo apuntado en trabajos previos, la existencia de factores que dificultan la necesaria igualdad de genero. De forma similar, los resultados también avalan la idea de que la cultura empresarial y los estereotipos de género impiden la diferenciación efectiva de los estilos directivos femenino y masculino, al menos en cuanto a la forma de gestionar la RSE.

Por ultimo, cabe señalar la necesidad de realizar nuevos estudios que permitan superar las limitaciones de éste relacionadas, sobre todo, con el reducido tamaño de la muestra y a su falta de representatividad por el sistema de elección utilizado. Esto ayudaría a validar y generalizar los resultados obtenidos.

\section{BIBLIOGRAFÍA}

AECA. Marco conceptual de la Responsabilidad Social Corporativa. 2004.

ARCAS LARIO, Narciso y BRIONES PEÑALVER, Antonio Juan. Responsabilidad Social Empresarial de las Organizaciones de la Economía Social, Valoración de la misma en las empresas de la Región de Murcia. CIRIEC-España, Revista de Economía Pública, Social y Cooperativa, $\mathrm{n}^{\circ}$ 65, 2009, p. 143-161.

REVESCO No 105 - MONOGRÁFICO: La economía social y la igualdad de género -

ISSN: 1885-8031 - www.ucm.es/info/revesco 
ASOCIACIÓN NAVARRA DE EMPRESAS LABORALES (ANEL). Primera encuesta sobre el papel de la mujer en las empresas asociadas a ANEL. ANEL Horizonte Empresarial, $\mathrm{n}^{\circ}$ 23, 2003, p. 11-15.

AUSIN GÓMEZ, Jose Manuel (Dir. y coord.). Libro Blanco de las Sociedades Cooperativas y Laborales de Extremadura. Badajoz: Consejería de Trabajo, 2002. 548 p. ISBN: 84-6880373-1.

BARBERÁ HEREDIA, Esther, RAMOS LÓPEZ, Amparo. y SARRIÓ CATALÁ, Maite. Mujeres directivas ante el tercer milenio: el proyecto Nowdi XXI, Papeles del psicólogo: revista del Colegio Oficial de Psicólogos, nº 75, 2000.

BERENGUER CONTRÍ, Gloria; CASTELLVÍ, Josefa Mª; CERVER ROMERO, Elvira; JUAN, Carmen; TORCAL TOMÁS, V. Ramón. y DE LA TORRE FERNÁNDEZ, Amparo. El laberinto de cristal. Un estudio sobre el acceso de las mujeres a los puestos de dirección en las cooperativas de trabajo asociado valencianas. Dificultades y oportunidades. Valencia: FVECTA, 1999. 126 p. ISBN: 84-370-5860-0.

BERENGUER CONTRÍ, Gloria, CERVER ROMERO, Elvira, DE LA TORRE FERNÁNDEZ, Amparo y TORCAL TOMÁS, V. Ramón. El estilo directivo de las mujeres y su influencia sobre la gestión del equipo de trabajo en las cooperativas valencianas. CIRIEC-España, Revista de Economía Pública, Social y Cooperativa, $\mathrm{n}^{\circ}$ 50, noviembre, 2004, p. 123-149.

CEPES, Anuario de la Economía Social 2007-2008, Madrid, 2009, p. 1-148. Disponible en Internet: http://www.cepes.es/media/docs/Anuario_CEPES_2008_Baja_Res.pdf.

CHAVES ÁVILA, Rafael; RIBAS BONET, María Antonia y SAJARDO MORENO, Antonia. Cumplimiento del primer principio: análisis de la discriminación por género en las cooperativas españolas. Revista de la Cooperación Internacional, n ${ }^{\circ}$ 1, 2005, p. 101118.

CHURCHILL, Gilbert. A Paradigm for Developing Better Measures of Marketing Constructs, Journal of Marketing Research, $\mathrm{n}^{\circ}$ 16, 1979, p. 64-73.

COMISIÓN DE LAS COMUNIDADES EUROPEAS. Libro Verde Fomentar un marco europeo para la responsabilidad social de las empresas, Bruselas, 2001, p. 1-35. Disponible en Internet: http://eurlex.europa.eu/LexUriServ/LexUriServ.do?uri=COM:2001:0366:FIN:ES:PDF. 


\section{CONFEDERACIÓN ESPAÑOLA DE COOPERATIVAS DE TRABAJO ASOCIADO} (COCETA). Estudio sobre la realidad social y laboral de las mujeres en el Cooperativismo de trabajo asociado en España, Madrid. Disponible en Internet: http://www.coceta.com.

DAVIDSON, Marilyn, y COOPER, Cary L. Shattering the glass ceiling: The woman manager. Pau1 Chapman Publishing, 1992. 192 p. ISBN: 1853961329.

DE LA CUESTA GONZÁLEZ, Marta y VALOR MARTÍNEZ, Carmen. Responsabilidad social de la empresa. Concepto, medición y desarrollo en España, Boletín ICE Económico, $\mathrm{n}^{\circ} 2755,2003$, p. 7-19.

ECHEBARRIA MIGUEL, Carmen y LARRAÑAGA SARRIEGUI, Mercedes. La igualdad entre mujeres y hombres: una asignatura pendiente. CIRIEC - España. Revista de economía pública, social y cooperativa, $\mathrm{n}^{\circ} .50,2004$, p. 11-35.

ELIO CEMBORAIN, Eunate. Responsabilidad social en las cooperativas: igualdad de oportunidades entre hombres y mujeres. Revista Vasca De Economía Social Gizarte Ekonomiaren Euskal Aldizkaria, nº. 2, 2006 , p. 35-71.

ESTEBAN SALVADOR, María Luisa. Consejos de administración y creación de valor: la perspectiva del género. Tesis doctoral, 2007, Universidad de Zaragoza.

ESTEBAN SALVADOR, María Luisa; GARGALLO CASTEL, Ana y PÉREZ SANZ, Francisco Javier. Composición del consejo rector y género en las cooperativas turolenses. REVESCO - Revista de Estudios Cooperativos, $\mathrm{n}^{\circ}$ 101, 2010, p. 7-27.

FERNÁNDEZ-PALACÍN， Fernando; LÓPEZ-FERNÁNDEZ， Macarena; MAEZTUHERRERA, Inmaculada y MARTÍN-PRIUS, Antonio. El techo de cristal en las pequeñas y medianas empresas. Revista de Estudios Empresariales. Segunda época. № 1, 2010, p. $231-247$.

FORÉTICA. Informe Forética 2008, Evolución de la Responsabilidad Social de las Empresas en España. 2008. Madrid. FORÉTICA, 2008. Disponible en Internet: http://www.foretica.es/recursos/doc/Biblioteca/Informes/36900_16121612200821230.pdf.

GRANDE ESTEBAN, Ildefonso y ABASCAL FERÁNDEZ, Elena. Fundamentos y técnicas de investigación comercial. Madrid: ESIC, 2007. ISBN: 9788473565141.

HELGESEN, Sally. La ventaja de ser mujer. Colección Mujeres en Management. Barcelona: Ediciones Granica, 1990. 252p. ISBN: 84-7577-331-1.

IBAÑEZ PASCUAL, Marta. La Segregación Ocupacional por Sexo a Examen: Características Personales, de los Puestos y de las Empresas Asociadas a las Ocupaciones

REVESCO No 105 - MONOGRÁFICO: La economía social y la igualdad de género -

ISSN: 1885-8031 - www.ucm.es/info/revesco 
Masculinas y Femeninas". Revista Española de Investigaciones Sociológicas, $\mathrm{n}^{\circ}$ 123, 2008, p. 87-122.

IBAÑEZ PASCUAL, Marta. Al otro lado de la Segregación Ocupacional por Sexo. Hombres en Ocupaciones Femeninas y Mujeres en Ocupaciones Masculinas. Revista Internacional de Sociología, vol. $68 \mathrm{n}^{\circ} 1,2010$, p. 145-164.

INSTITUTO CÀTALA DE LA DONA i DONES DE LA UNIÓ DE PAGESOS: Gènere, agricultura i representació de les dones en les cooperatives agràries de Catalunya. Barcelona: Institut Català de la Dona, 2003. 64p. ISBN: 978-84-393-6071-1.

LÁZARO, Nieves; MOLTÓ, Ma Luisa y SÁNCHEZ, R. Desigualdades de género en el trabajo. La brecha de género en el empleo y la distribución de las tareas de cuidado. CIRIEC - España. Revista de economía pública, social y cooperativa, nº. 50, 2004, p. 5575.

LODEN, Marilyn. Femenine leadership, or How to succeed in business without being one of the boys. London: Times Books, 1987. 306 p. ISBN: 0812912403.

MAHER, Karen J. Gender-related stereotypes of transformational and transactional leadership, Sex Roles, vol. 37 n 3-4, 1997, p. 209-225.

MARÍN, Longinos; ARCAS LARIO, Narciso y CORTÉS GRACÍA, Francisco J. Guía práctica para la elaboración de memorias de RSE en cooperativas agroalimentarias. Almería: Fundación Cajamar. 2010. ISBN: 978-84-937759-1-9.

MATEOS DE CABO, Ruth; ESCOT MANGAS, Lorenzo y GIMENO NOGUÉS, Ricardo. Análisis de la presencia de la mujer en los Consejos de Administración de las mil mayores empresas españolas. Fundación de las Cajas de Ahorros. Documento de trabajo 263, 2006.

MINISTERIO DE TRABAJO E INMIGRACIÓN, Datos Estadísticos de Economía Social. Disponible en Internet: http://www.mtin.es/es/sec_trabajo/autonomos/economiasoc/EconomiaSocial/estadisticas/index.htm.

POWELL, Gary N. Women and men in management. Sage: California, 1991.

RAMOS LÓPEZ, Amparo. Mujeres directivas: un valor en alza para las organizaciones laborales. Cuadernos de Geografía, no 78, 2005, p. 191-214.

RAMOS LÓPEZ, Amparo; BARBERÁ HEREDIA, Esther y SARRIÓ CATALÁ, Maite. Mujeres directivas, espacio de poder y relaciones de género. Anuario de Psicología, vol. 34 no 2, 2003, p. 267-278.

REVESCO No 105 - MONOGRÁFICO: La economía social y la igualdad de género -

ISSN: 1885-8031 - www.ucm.es/info/revesco 
REDONDO CRISTÓBAL, Mercedes y JIMENO DE LA MAZA, Francisco Javier. El escenario de la desigualdad de género en la esfera de los negocios en cuatro actos. Disponible en Internet en: http://wzar.unizar.es/siem/articulos/Premios/Escenario.pdf.

RIBAS BONET, María Antonia. Mujeres y cooperativismo en la Comunidad Autónoma del País Vasco. Revista vasca de economía social = Gizarte ekonomiaren euskal aldizkaria, No. 2, 2006, p. 153-175.

RIBAS BONET, María Antonia. Mujer y trabajo en la Economía Social. Palma de Mallorca: Universidad de Islas Baleares, 2010. 368p, ISBN: 978-84-8384-148-8.

RIBAS BONET, María Antonia y SAJARDO MORENO, Antonia. La desigualdad participación de hombres y mujeres en la economía social: Teorías explicativas, CIRIEC España. Revista de economía pública, social y cooperativa, n. 50, 2004, p. 77-103.

RIBAS BONET, María Antonia y SAJARDO MORENO, Antonia. La diferente participación laboral de las mujeres entre las cooperativas y las sociedades laborales, CIRIEC - España. Revista de economía pública, social y cooperativa, $\mathrm{n}^{\circ}$. 52, 2005, p. 267-278.

ROMERO RAMÍREZ, Antonio J. y PÉREZ GARCÍA, Miguel. Estudio psicológico de una muestra de cooperativas de trabajo asociado de Andalucía, Revista del Ministerio de Trabajo y Asuntos Sociales, $\mathrm{n}^{\circ}$ 26, 2000, p. 113-127.

SAJARDO MORENO, Antonia; RIBAS BONET, Ma Antonia; BENAVENT SANCHO, Matilde; SAZ GIL, Isabel; SERRA YOLDI, Inmaculada y VILAR FIGUEIRIDO, Montserrat. La Responsabilidad Social Interna de las empresas en España. Valencia: Tirant lo Blanch, 2009. 263 p. ISBN: 9788498767254.

SEGERMAN-PECK, Lily M. Networking and mentoring. A woman's guide. Judy Piatkus Ltd, 1991. 192 p. ISBN: 0749910550.

SERVER IZQUIERDO, Ricardo y CAPÓ VICEDO, Jordi. La Responsabilidad Social Empresarial en un contexto de crisis. Repercusión en las Sociedades Cooperativas, CIRIEC-España, Revista de Economía Pública, Social y Cooperativa, nº 65, 2009, p. 7-31. WIRTH, Linda. Breaking trough the Glass Ceiling: women in management, International Labour Office: Geneva, 2001.

REVESCO No 105 - MONOGRÁFICO: La economía social y la igualdad de género ISSN: 1885-8031 - www.ucm.es/info/revesco 